\title{
Articulações Intrapartidárias e Desempenho Eleitoral no Brasil*
}

\author{
George Avelino ${ }^{1}$ \\ Ciro Biderman ${ }^{2}$ \\ Leonardo S. Barone ${ }^{3}$
}

${ }^{1}$ Professor Associado da Fundação Getulio Vargas (FGV), São Paulo. E-mail: george.avelino@fgv.br.

Professor no curso de mestrado e doutorado em Administração Pública da Escola de Administração de Empresas de São Paulo (EAESP/FGV). E-mail: ciro.biderman@fgv.br.

${ }^{3}$ Doutorando em Administração Pública e Governo e pesquisador do Centro de Estudos em Economia e Política do Setor Público na Fundação Getulio Vargas (FGV-SP). E-mail: leonardo.barone@gmail.com.

\section{INTRODUÇÃO}

$\mathrm{O}$ s partidos brasileiros são importantes eleitoralmente? Durante muito tempo, houve um quase consenso entre os pesquisadores na resposta negativa a esta pergunta. Após a definição das candidaturas, as campanhas eleitorais seriam conduzidas pelos candidatos de forma individual e isolada. Entretanto, pesquisas relativamente recentes questionam a abordagem tradicional apresentando dados empíricos que sugerem uma perspectiva mais matizada quanto à importância eleitoral dos partidos. Esta divergência entre o que seria esperado e o que é observado colocou um novo problema de pesquisa em busca de explicação.

Por exemplo, alguns autores têm atestado a queda da volatilidade eleitoral no Brasil desde antes da redemocratização ${ }^{1}$. Apesar de esta queda não ter sido homogênea, ela tem sido consistente ao longo das últimas décadas e deve colocar a volatilidade eleitoral brasileira perto da média dos países democráticos. De acordo com Mainwaring e Torcal (2006), a média da volatilidade eleitoral no Brasil entre 1982 e 2002 foi de $24,1 \%$, um valor mediano em um grupo de 39 países majoritaria-

\footnotetext{
* Este artigo é um dos produtos da pesquisa, Instituições Políticas e Gastos Públicos: Um Estudo Comparativo do Estados Brasileiros, projeto temático da Fundação de Amparo à Pesquisa do Estado de São Paulo (Fapesp).
}

DADOS - Revista de Ciências Sociais, Rio de Janeiro, vol. 55, no4, 2012, pp. 987 a 1013. 
mente da Europa e das Américas ${ }^{2}$. Esta queda na volatilidade é surpreendente, dado o paradigma dos "partidos fracos", e tem se reproduzido nas eleições estaduais ${ }^{3}$.

Em um artigo recente, Carneiro e Almeida (2008) deram mais um passo na compreensão da queda da volatilidade, ao demonstrarem que os altos níveis de correlação do desempenho eleitoral dos partidos - queda na volatilidade - ocorrem também nos municípios brasileiros. Especificamente para os propósitos deste artigo, esse trabalho salientou uma habilidade inesperada dos partidos de organizar seus esforços eleitorais não somente entre as eleições de um mesmo nível (nacional, estadual ou municipal), como também para eleições entre diferentes níveis, o que sugere capacidade de articulação entre os níveis de organização partidária ${ }^{4}$.

Neste artigo, pretendemos contribuir para esta discussão ao especificar o efeito que a eleição de um prefeito pode ter sobre o desempenho de seu partido, no mesmo município, nas eleições proporcionais estaduais realizadas dois anos depois. Consideramos que um partido que elege um prefeito passa a ter uma vantagem eleitoral potencial sobre os demais partidos naquele município ${ }^{5}$; entretanto, a realização dessa vantagem nas eleições seguintes vai depender da articulação entre a organização partidária municipal e a estadual. O foco nos efeitos da eleição de um prefeito nas eleições proporcionais subsequentes nos ajudaria a avançar um pouco mais na compreensão da queda na volatilidade, através da análise das relações intrapartidárias, ou seja, o esforço empreendido pelas organizações partidárias municipais para traduzir a vantagem adquirida em transferência de votos para os candidatos do partido que concorrem em eleições estaduais subsequentes.

Nós afirmamos que, se não houver articulação entre os diferentes níveis da organização partidária, a eleição de um prefeito não deveria implicar mais votos para o seu partido na eleição proporcional subsequente de âmbito estadual. Em outras palavras, se não existir articulação intrapartidária não haveria motivo para um prefeito eleito por partido cooperar sistematicamente com os candidatos de seu partido nas eleições que ocorrem dois anos depois dele ser eleito. Portanto, se encontrarmos evidências de causalidade entre a eleição de um prefeito e os votos nas eleições proporcionais do seu partido na eleição seguinte, interpretaremos esse resultado como evidência de que a articulação intrapartidária tem importância nas eleições brasileiras. 
Para identificar o efeito causal que a eleição de um prefeito pode ter sobre o desempenho de seu partido nas eleições para deputados estaduais e federais, utilizamos um modelo de regressão descontínua (RDD, em inglês). O RDD permite que comparemos, em um mesmo município, o partido que ganhou a eleição para prefeito (por uma pequena margem) e o partido que a perdeu. Estes dois partidos podem ser considerados como uma estimativa para o contrafactual um do outro, tendo em vista que a definição dos candidatos vencedores está relacionada à pequena variação aleatória dos votos que pode ocorrer devido ao clima no dia das eleições ou a outros fatores exógenos.

Nossos resultados sugerem que eleger um prefeito (mesmo com margem de apenas $1 \%$ ) aumentaria os votos para o seu partido nas eleições proporcionais subsequentes para deputado federal ou estadual. Nosso objetivo neste artigo não é analisar mais detidamente os mecanismos causais específicos, ou seja, como um partido consegue realizar a vantagem adquirida através da eleição do prefeito e transferir votos para os seus candidatos; entretanto, a identificação desta causalidade é uma descoberta importante para começarmos a entender as articulações partidárias entre diferentes níveis de governo no sistema político brasileiro, uma variável crucial para a compreensão da política federativa, conforme apontado desde Riker (1964). Essa descoberta também é importante para avançarmos a nossa compreensão sobre o tamanho legislativo dos partidos na Câmara Federal e nas Assembleias Estaduais, uma variável crítica no processo de formação das coalizões governamentais.

Além desta introdução, este trabalho contém outras cinco seções. A próxima seção aborda a questão da articulação intrapartidárias em sistemas políticos organizados em vários níveis de governo. A seção seguinte discute alguns aspectos do sistema político brasileiro relevantes para a análise que se seguirá, particularmente, o sistema federativo e a organização do calendário eleitoral. A terceira apresenta a base de dados, o desenho da pesquisa e a discussão dos principais resultados encontrados; a quarta seção dedica-se a testes de robustez. Finalmente, a quinta seção sumariza e conclui.

\section{ORGANIZAÇÃO INTRAPARTIDÁRIA E COMPETIÇÃO ELEITORAL}

A atividade partidária em diferentes níveis territoriais de governo aumentou com a descentralização política ocorrida no Brasil e em outros 
países. Apesar da expectativa de que a descentralização impusesse maiores desafios organizacionais sobre os partidos políticos, uma vez que estes teriam de administrar a interação entre as arenas eleitorais locais e nacionais, ainda temos conhecimento limitado acerca de como os partidos se desempenham neste tipo de articulação ${ }^{6}$.

A habilidade que os partidos demonstram para articular as ações nos diferentes níveis nos informará muito sobre a natureza do sistema político ${ }^{7}$. Como os partidos administram articulações partidárias entre políticos nos diferentes níveis eleitorais? O tipo de articulação intrapartidária dependerá de como os partidos são organizados ou, mais especificamente, do grau de centralização partidária. Em partidos centralizados, a liderança nacional é responsável pelas decisões partidárias cruciais, como o recrutamento de lideranças locais, a seleção de candidatos e a estratégia de coligações e coalizões. Neste tipo de partido, conflitos intrapartidários tendem ser raros, uma vez que a integração entre os diferentes níveis eleitorais é definida ex ante pelos estatutos partidários. Em partidos cuja organização é mais descentralizada, as organizações locais mantêm alguma autonomia quando se defrontam com líderes nacionais, e a articulação entre diferentes arenas eleitorais será consequência de negociações entre as lideranças nacionais e locais ${ }^{8}$.

Este artigo está preocupado com um tipo específico de articulação intrapartidária: o efeito coattail reverso das organizações partidárias locais para níveis mais elevados de competição eleitoral. A existência de coattails eleitorais é apontada com evidência de articulação intrapartidária ao associar o desempenho eleitoral dos candidatos do partido em diferentes níveis ${ }^{9}$. Estudos sobre este tipo de efeito eleitoral são comuns na literatura sobre a política norte-americana, mas raros em estudos sobre outros sistemas políticos ${ }^{10}$. Pode-se entender este efeito como a capacidade de um candidato de primeira linha do partido, normalmente os candidatos a cargos executivos, de transferir votos para seus companheiros de partido que sejam candidatos em níveis mais locais de competição eleitoral. O exemplo mais comum na política norte-americana associa o voto para presidente com o voto para deputado federal no distrito eleitoral.

Os efeitos coattail reversos também se referem às transferências intrapartidárias de votos, mas desta vez observadas de uma perspectiva de baixo para cima, ou seja, a habilidade das organizações partidárias lo- 
cais de transferir votos para candidatos do partido em eleições disputadas em distritos mais amplos. Como será desenvolvido mais adiante, assumimos que este tipo de transferência de votos, no caso brasileiro, seria evidência das articulações entre as seções locais e estaduais do mesmo partido.

Mais especificamente, analisamos se os prefeitos são capazes de transferir votos para os candidatos de seu partido nas eleições para os cargos legislativos estaduais e federais. Alguns autores já argumentaram sobre a existência do efeito coattail reverso no Brasil; entretanto, eles não focaram sua atenção para os prefeitos como uma importante engrenagem para o desempenho eleitoral do partido nas eleições proporcionais subsequentes ${ }^{11}$.

Antes de lidar com as especificidades da análise empírica, vejamos algumas informações sobre o sistema político, assim com a discussão sobre a decisão das organizações locais em apoiarem os candidatos de seu partido que concorrem em distritos mais amplos.

\section{O SISTEMA POLÍTICO BRASILEIRO: FEDERALISMO E ORGANIZAÇÃO PARTIDÁRIA}

Ainda que o sistema político brasileiro apresente uma combinação rara de fórmulas eleitorais, o calendário eleitoral adquiriu considerável estabilidade. De acordo com a regra em vigor desde 1994, as eleições estaduais e nacionais são realizadas simultaneamente, com um intervalo de dois anos para as eleições municipais.

Detalhadamente, nas eleições nacionais e estaduais, presidente e governadores de estados são eleitos para um mandato de quatro anos em um regime majoritário de dois turnos, com uma disputa entre o primeiro e o segundo candidatos mais votados se o mais votado não atingir mais que $50 \%$ dos votos no primeiro turno. Membros de ambas as Câmaras Estaduais e Federal são eleitos também para um período de quatro anos, em um modelo proporcional estadual de lista aberta. Finalmente, senadores também são eleitos em eleições estaduais para mandatos de oito anos; o Senado Federal é renovado a cada quatro anos, em um sistema de um terço e dois terços, por meio de eleições majoritárias também realizadas simultaneamente com as eleições nacionais e estaduais. 
As eleições municipais são realizadas a cada quatro anos para eleger tanto o prefeito como os vereadores para um mandato de mesmo período. Em cada município, o prefeito é eleito por meio de sistema majoritário de turno único, e os vereadores são eleitos por meio de um regime proporcional de lista aberta ${ }^{12}$.

Ao contrário da maioria das federações, que são organizadas por meio da relação entre o governo central e os governos estaduais, ou provinciais, o federalismo brasileiro é organizado a partir da relação entre três níveis de governo, uma vez que os municípios também são reconhecidos como fontes soberanas de poder político. Os prefeitos têm autoridade sobre políticas públicas sob sua jurisdição; e esta autoridade aumentou com a descentralização promovida a partir da Constituição de 1988, ao delegar aos municípios a implementação de importantes políticas públicas, tais como educação e saúde. Como resultado, os cargos municipais são disputados e as arenas municipais aumentaram sua importância como distritos eleitorais básicos e loci de competição política ${ }^{13}$.

Devido a esta peculiaridade do federalismo brasileiro, não é surpreendente que a organização dos partidos brasileiros seja relativamente descentralizada. Tipicamente, os partidos têm uma estrutura baseada em diretórios municipais, que estão encarregados de assuntos rotineiros dos partidos, tal como o recrutamento de novos membros. Apesar de intervenções ocasionais de órgãos hierarquicamente superiores, as convenções municipais detêm autonomia considerável nas decisões sobre campanhas municipais, sobre a seleção de candidatos a prefeito e vereadores, sobre a definição de propostas políticas, estratégias de coalizão etc. Por fim, as convenções municipais também selecionam delegados municipais para as convenções partidárias estaduais, que decidem sobre os mesmos assuntos no nível estadual e selecionam os delegados estaduais para as convenções partidárias nacionais ${ }^{14}$. Desta forma, embora exista ordem hierárquica claramente definida entre as instâncias do partido, as cadeias de delegação entre a direção nacional e as direções estaduais e - muito importante para os nossos propósitos - entre estas últimas e as direções municipais preveem razoável grau de liberdade aos líderes partidários locais ${ }^{15}$.

Desta forma, a singularidade do Brasil frente a outros países é a de que o espaço territorial que define a unidade primordial de organização partidária corresponde a uma fonte constitucional de autoridade polí- 
tica, selecionada por meio de eleições competitivas, e responsável por políticas públicas importantes para a vida da maioria dos eleitores.

Resumindo as duas últimas seções, a lealdade partidária das lideranças municipais aos candidatos de seu partido, o efeito coattail eleitoral reverso, não deveria ser algo esperado por motivos teóricos e empíricos. Do ponto de vista teórico, as análises sobre coattails eleitorais quase sempre assumem que estes efeitos ocorrem de cima para baixo, ou seja, dos cargos majoritários em distritos mais amplos para os cargos proporcionais em distritos mais restritos. Do ponto de vista empírico, temos outros dois motivos. Primeiro, pela singularidade do federalismo brasileiro, com a inclusão dos municípios como fontes autônomas de poder, e seu correspondente na organização partidária, o que enfraqueceria as relações das organizações municipais com as organizações superiores do partido. Segundo, porque tratamos de eleições que não são simultâneas e que ocorrem com um longo intervalo de dois anos, características que dificultariam a ocorrência de qualquer tipo de coattail eleitoral. Portanto, se encontrarmos a ocorrência do efeito coattail reverso, mesmo sob estas condições adversas, poderíamos estar confiantes de que este efeito está relacionado à articulação vertical dos par$\operatorname{tidos}^{16}$.

Mas como podemos isolar o efeito causal de eleger um prefeito sobre o desempenho eleitoral posterior do partido de outros potenciais efeitos causais?

\section{BASE DE DADOS, ESTRATÉGIA DE IDENTIFICAÇÃO E PRINCIPAIS RESULTADOS}

Os dados eleitorais utilizados neste artigo foram obtidos do Tribunal Superior Eleitoral (TSE). Temos informações detalhadas tanto da eleição municipal de 2008 como da eleição estadual e nacional de 2010. Começamos por agregar as votações para candidatos por município, cargo e partido. Para as eleições de 2008, em cada município filtramos apenas os partidos que venceram as eleições para prefeito ou ficaram em segundo lugar, restando, portanto, dois partidos por município. Também eliminamos municípios com segundo turno e municípios com apenas um competidor para a eleição municipal (garantindo que cada município tivesse dois partidos relevantes $)^{17}$. Essas exclusões nos deixaram com 5.221 dos 5.564 municípios brasileiros. Para medir o desempenho dos partidos no município nas eleições de 2010, nós sim- 
plesmente agregamos os votos (nominais e na legenda) dados aos partidos especificados acima - primeiros e segundos colocados nas eleições de 2008 - tanto para deputado federal como para deputado estadual.

Para identificar se há articulação intrapartidária no Brasil, exploramos uma oportunidade dada pelas regras eleitorais brasileiras e discutida anteriormente neste artigo. No Brasil, desde 1994, existem eleições a cada dois anos, alternando entre eleições federais e estaduais (1994, 1998 etc.) e eleições locais (1996, 2000 etc.). A hipótese nula (de que os partidos não se articulam entre os níveis municipais e estaduais) é de que a eleição de um prefeito por um partido não teria impacto (causal) nos votos do mesmo partido na eleição proporcional subsequente.

É sempre importante lembrar que a existência de correlação entre eleitores dos partidos nas diferentes eleições, discutida nas seções anteriores, não deve ser considerada como evidência de algum tipo de causalidade. Nós afirmamos que, se não houver articulação entre os diferentes níveis da organização partidária, não esperaríamos que a eleição de um prefeito implicasse mais votos para o seu partido na eleição proporcional subsequente de âmbito estadual. Consequentemente, se encontrarmos evidências da direção da causalidade entre a eleição de um prefeito e os votos nas eleições proporcionais do seu partido na eleição seguinte, interpretaremos esse resultado como evidência de que os partidos têm importância nas eleições brasileiras.

O problema para identificar o efeito da eleição de um prefeito no desempenho partidário decorre da possibilidade de que os votos do partido em um dado município nas eleições estaduais sejam determinados por fatores não observáveis pelo pesquisador. Um partido forte em um município pode ter uma quantidade maior de votos em qualquer eleição mesmo sem coordenação partidária interna. Tal como em outras situações de pesquisa, este problema resulta da impossibilidade de que um partido simultaneamente ganhe e perca a mesma eleição para prefeito. Para lidar com esse problema clássico de endogeneidade, comparamos cidades nas quais o partido venceu a eleição por uma diferença marginal. Lee (2008) demonstra que essa estratégia fornece uma variação quase-aleatória entre vencedores e perdedores. $\mathrm{O}$ argumento é que quanto mais próximos os resultados de uma eleição mais o partido vencedor seria determinado aleatoriamente, por algum componente imprevisível no comportamento do eleitor ${ }^{18}$. 
Em outras palavras, o caráter aleatório da vitória nas eleições para prefeito é a chave para contornar o problema de endogeneidade descrito acima. Para os propósitos deste artigo, partidos com desempenhos eleitorais muito próximos são também muito semelhantes - devem ter mais ou menos a mesma influência no município - exceto que um logrou eleger o prefeito e o outro não. Essa semelhança torna possível simular a situação em que um mesmo partido simultaneamente ganhe e perca as eleições para prefeito, ou seja, comparar um partido com ele mesmo, o que nos permite identificar o efeito da eleição do prefeito.

Para encontrar tal efeito estimamos variações da seguinte função:

$v_{m, p, t+2}=\alpha+\delta d_{m, p, t}+V\left(x_{m, p, t} ; \beta\right)+\sum_{k} \gamma k^{c^{k}} m, p, t+\eta_{m, p, t}$

onde $v_{m, p, t+2}$ representa a proporção de votos para deputado estadual ou federal no município $m$ para o partido $p$ na eleição ocorrida em $t+2$ (nesse caso, 2010); $d_{m, p, t}$ é uma variável binária que assume valor 1 se o partido venceu a eleição para prefeito em $t$ (nesse caso, 2008) e 0 se ele ficou em segundo lugar; $x_{m, p, t}$ representa a margem de vitória na eleição municipal, isto é, a proporção de votos do prefeito mais votado menos a proporção de votos do segundo colocado no município $m ; V\left(x_{m, p, t} ; \beta\right)$ é uma função contínua da margem de vitória parametrizada por $\beta ; c_{m, p, t}^{k}$ representa uma covariável $k$ relacionada às características do município $m$, partido $p$ no ano $t$ onde, para fins de generalidade, mantivemos a possibilidade de $k$ covariáveis; e $\eta_{m, p, t}$ é um termo de erro com os seus atributos geralmente necessários (e desejados). $\alpha$, $\beta$ s e $\gamma$ s são parâmetros a serem estimados pela regressão.

É importante destacar aqui que, apesar de utilizarmos um subscrito para o tempo, não temos um painel de dados. Na realidade, as variáveis independentes estão dois anos defasadas em relação à dependente. Assim, o subscrito do tempo serve apenas para enfatizar que estamos trabalhando com dados defasados. Utilizar dados com dois anos de defasagem já garante um pouco de exogeneidade como explorado por Carneiro e Almeida (2008). Assim temos variáveis de 2008 entre as variáveis independentes e variáveis de 2010 para a variável dependente. Em princípio podemos montar um painel adicionando dados de 2006 regredidos contra 2004, dados de 2002 regredidos contra dados de 2000 etc. No entanto, neste artigo trabalhamos apenas com duas eleições defasadas (2008 e 2010). 
Um outro ponto relevante a ser destacado é que essa estratégia evita um problema usual na estimação de regressões em proporções com múltiplos partidos. Nesses casos, se a variável dependente representar a proporção de votos de um partido e todos os partidos estiverem envolvidos na regressão, a soma das proporções de votos para um determinado município será sempre igual a um, gerando um problema com a hipótese de independência das observações. Esse problema foi tratado na literatura por Katz e King (1999), Tomz, Tucker e Wittenberg (2002), entre outros. No nosso caso, como somamos as proporções dos dois partidos mais bem votados por município, a soma dos votos não é necessariamente $\mathrm{um}^{19}$.

Claro que, potencialmente, os dois partidos que ficaram em primeiro ou segundo poderiam também obter todos os votos para o legislativo dois anos depois. No nosso caso, entretanto, não há nenhuma observação acima de 95\% para deputados federais e apenas dez observações acima de $95 \%$ para deputados estaduais. De qualquer modo, dado esse problema potencial, rodamos as regressões novamente eliminando da amostra os municípios para os quais a soma de votos para deputado federal ou deputado estadual representava mais do que $80 \%$ do total de votos no município. O efeito dessa mudança é o de aumentar o impacto da eleição do prefeito na proporção dos votos para deputados no pleito seguinte. Vale destacar que, quando reduzimos a amostra para as observações em que a diferença entre o primeiro e o segundo lugar na eleição para prefeito estivesse abaixo de 5\%, não há observações em que a soma dos dois partidos esteja acima de $80 \%$ dos votos para deputado federal, e apenas dez observações para deputado estadual.

Ignorando o viés de seleção, é evidente que $\delta$ identifica o efeito do prefeito ter sido eleito no desempenho de seu partido na eleição subsequente. Esse efeito denominamos "efeito partidário" pois exige que o prefeito se esforce para obter votos para os deputados de seu partido (não para candidatos de sua preferência que estivessem em qualquer partido). Em outras palavras, se fosse possível controlar todas as fontes de viés a partir das variáveis observadas poderíamos afirmar que o termo $d_{m, p, t}$ mede o efeito causal do prefeito pertencer a um determinado partido nos votos desse mesmo partido no pleito estadual dois anos depois.

Para entender um pouco melhor a estratégia de identificação precisamos refletir sobre a fonte de viés da medida de efeito partidário. Um 
partido forte em um determinado município deve ter uma performance boa em qualquer eleição nesse mesmo município. Ou seja, os votos do partido em um município em uma eleição devem estar correlacionados com a votação desse partido na eleição seguinte.

Assim, precisaríamos isolar o efeito do prefeito na eleição para deputado ao controlar pela força do partido (independente do prefeito) nesse município. Uma variável (observada) que poderia realizar esse controle é a proporção de votos para vereador nas eleições de 2008. Adicionalmente, tal com discutido anteriormente, utilizamos como estratégia de identificação a regressão descontínua que consiste em observar o impacto apenas em eleições com uma margem apertada de vitória.

Tabela 1

Impacto da Eleição para Prefeito (2008) na Eleição para Deputado Federal Subsequente (2010) por Diferentes Especificações e Amostras

\begin{tabular}{l|c|c}
\hline Covariadas e Restrição Amostral & OLS & Municípios \\
\hline Amostra completa & $0,0553^{*}$ & 5.211 \\
Amostra completa controlando por votos para vereadores & $0,0314^{*}$ & 5.211 \\
Margem de vitória no município < 5\% & $0,0401^{*}$ & 1.374 \\
Margem de vitória no município < 3\% & $0,0428^{*}$ & 823 \\
Margem de vitória no município < 1\% & $0,0365^{*}$ & 266 \\
Margem de vitória no município < 1\% e controlando por votos & & \\
para vereadores & $0,0340^{*}$ & 266 \\
\hline
\end{tabular}

Fonte: Tribunal Superior Eleitoral (TSE).

* Significativo a $1 \%$; ** significativo a 5\%; *** significativo a $10 \%$ (desvio padrão robusto com cluster por município).

Na primeira linha apresentamos o efeito partido "incondicional" 20 , ou seja, a presentamos essencialmente a correlação entre os votos para deputado federal em 2010 em um determinado município e o fato de o partido ter eleito o prefeito desse município em 2008 independentemente da margem de vitória. O efeito incondicional implica aumento de 5,5\% em valores absolutos no desempenho do partido do prefeito nas eleições para deputado federal. Considerando o valor de base de cerca de $15 \%$ na amostra - percentual médio da votação dos partidos que ficaram em primeiro ou segundo lugar nas eleições municipais para deputado federal no município ${ }^{21}$, a estimativa incondicional revela um impressionante aumento relativo de $37 \%$ nos votos para deputados federais em municípios nos quais o partido conseguiu eleger o prefeito. 
Conforme discutido acima, não acreditamos que esta seja uma boa estimativa do efeito causal partidário. A primeira estratégia é controlar pela votação que os candidatos a vereador do partido obtiveram no município. Essa variável contemporânea pode controlar por grande parte da endogeneidade no resultado da eleição subsequente se acreditarmos que poderíamos estar confundindo a influência do partido com inércia do poder dos membros do partido no município. De fato, ao adicionarmos essa variável de controle, o valor absoluto do efeito partidário é reduzido para 3\%. Apesar de introduzirmos o controle dos votos para vereador, este coeficiente é estatisticamente significante, mesmo a 99\%, e representa impacto substancioso: um aumento em torno de $20 \%$ em termos relativos na votação do partido para deputado federal no município em relação ao valor base.

Quando restringimos nossa amostra para os municípios em que a margem de vitória foi apertada, confirmamos nossa suspeita de que o efeito irrestrito e incondicional pode estar superestimando o efeito do partido na eleição subsequente. No entanto, as estimativas do efeito partidário são estatisticamente significantes (a 1\%) até para margens de vitória abaixo de 1\%. Nos 266 municípios onde a eleição foi definida com menos de $1 \%$ de margem, a votação subsequente para deputado federal de seu partido foram, em média, 3,7\% mais altas do que os votos para o candidato na segunda colocação. Mantendo essa amostra de municípios de eleição municipal apertada e adicionando os votos para vereador como variável de controle, o impacto é reduzido apenas levemente para $3,4 \%$.

Esses resultados reforçam nossa confiança nos pressupostos que adotamos para a análise por dois motivos: o efeito reduzido da introdução do controle dos votos para vereador indica que eleições muito apertadas são disputadas por partidos muito semelhantes. Além disso, esse resultado está acima do estimado quando não restringimos a amostra e adicionamos os votos para vereador do partido (linha 2), o que sugere que a variável de votos para vereador pode estar afetando "excessivamente" o efeito partidário, induzindo uma subestimativa do parâmetro real quando não restringimos a amostra para as eleições mais aper$\operatorname{tadas}^{22}$.

Para reforçar nossa confiança, testamos diferentes funções para $V(x ; \beta)$ uma vez que um problema relevante no desenho de regressão em descontinuidade é confundir descontinuidade com não linearidade. $\mathrm{Na}$ 
tabela reportamos apenas estimativas de uma especificação polinomial de quarto grau, mas os resultados são bastante resistentes à especificação funcional. Magnitude e significância não são afetadas por diferentes premissas da forma funcional da variável em análise - margem de vitória. Interpretamos esse resultado como um teste de robustez para o nosso resultado de que existe coattail reverso, ou seja, uma articulação entre os níveis do partido de tal sorte que os prefeitos atuam sistematicamente como cabos eleitorais para os candidatos a deputado federal de seus próprios partidos.

A afirmação de que o resultado é robusto parte, sobretudo, da estratégia de regressão descontínua discutida anteriormente. Essa estratégia tem sido amplamente utilizada na literatura de ciência política justamente se aproveitando da descontinuidade natural das eleições. Ainda que essa literatura tenha sido desenvolvida originalmente para as eleições norte-americanas, já existem diversas aplicações em outros países incluindo o Brasil (Brambor e Ceneviva, 2012; Brollo e Nannicini, 2012; Titiunik, 2009) justamente com eleições municipais.

\section{ALGUNS TESTES ADICIONAIS DE ROBUSTEZ}

Evidentemente, gostaríamos de testar um pouco mais a sensibilidade dos nossos resultados. Preliminarmente, gostaríamos de saber se a articulação intrapartidária, ou seja, a evidência de transferência de votos do prefeito para os candidatos proporcionais do mesmo partido é generalizada ou varia entre os partidos dos prefeitos eleitos. Em outras palavras, nós poderíamos estar atribuindo aos partidos em geral efeitos que se concentram em poucos partidos. Num segundo momento, nossos testes verificam se a articulação intrapartidária depende dos vínculos dos prefeitos com a coalizão governamental estadual e fede$\mathrm{ral}^{23}$.

Para saber se o efeito que encontramos é generalizado entre os partidos, permitimos que cada partido tenha um efeito distinto em termos do coattail reverso proposto neste artigo. Para isso adicionamos uma variável binária para cada partido e interagimos essa variável com a variável binária que indica se o partido ganhou ou perdeu a eleição (a nossa variável de tratamento). A introdução destas variáveis nos permitirá verificar se o efeito que encontramos é generalizado. Como é bem conhecido, não podemos adicionar todas as combinações possíveis, caso contrário teríamos multicolinearidade perfeita. Assim, ex- 
cluímos o partido com maior número de prefeituras, o Partido do Movimento Democrático Brasileiro (PMDB) ${ }^{24}$. Isso significa que os valores e magnitudes apresentados na Tabela 2 referem-se ao impacto dos prefeitos eleitos pelo PMDB no desempenho deste partido nas eleições estaduais.

Tabela 2

Impacto da Eleição para Prefeito (2008), controlando para a Heteregoneidade por Partido na Eleição para Deputado Federal Subsequente (2010) por Diferentes Especificações e Amostras

\begin{tabular}{l|c|c}
\hline Covariadas e Restrição Amostral & OLS & Municípios \\
\hline Amostra completa & $.0548774 *$ & 5.211 \\
Amostra completa controlando por votos para vereadores & $.0365019 *$ & 5.211 \\
Margem de vitória no município $<5 \%$ & $.0219211^{* *}$ & 1.374 \\
Margem de vitória no município $<3 \%$ & .0135927 & 823 \\
Margem de vitória no município $<1 \%$ & .0142511 & 266 \\
Margem de vitória no município $<1 \%$ e controlando por & & \\
votos para vereadores & .0181464 & 266 \\
\hline
\end{tabular}

Fonte: Tribunal Superior Eleitoral (TSE).

* Significativo a $1 \%$; ** significativo a $5 \%$; *** significativo a $10 \%$ (desvio padrão robusto com cluster por município).

As duas primeiras linhas apresentam um resultado muito semelhante ao encontrado sem os controles para os partidos. Em outras palavras, o PMDB aparenta ter nível de articulação intrapartidária próximo ao apresentado pelo conjunto dos partidos na Tabela 1. Entretanto, conforme restringimos a amostra, no entanto, acabamos perdendo precisão, como seria de se esperar ${ }^{25}$. Com margem de vitória menor do que $5 \%$ temos um coeficiente preciso a $5 \%$ porém com magnitude menor do que o estimado para a amostra sem a inclusão dos controles por partido. Finalmente, para a amostra considerando apenas os municípios para os quais a margem de vitória foi de 3\% ou 1\%, os coeficientes já não são significantes. Acreditamos que esse resultado se deva exclusivamente à redução no tamanho da amostra associada à adição de um número muito alto de novas variáveis. O que reforça essa interpretação é o fato de o resultado resistir para a amostra toda adicionando-se a proporção de votos para vereador do partido. Como argumentamos, essa última variável parece capturar boa parte da força do partido no município.

Uma outra hipótese explicativa seria que o PMDB em particular não está tão articulado como os demais partidos. Esta hipótese é imprová- 
vel, pois dada a presença do PMDB nos municípios brasileiros, este partido deve ter um comportamento muito parecido com a média. De fato, é possível testar se um partido está acima ou abaixo da média pemedebista observando o coeficiente da interação entre a variável binária do partido e a variável de tratamento. Observando os resultados da regressão para a amostra toda incluindo a proporção de votos para vereador como base, notamos que a articulação intrapartidária é menor para quatro partidos (Partido Republicano Brasileiro (PRB), Partido Democrático Trabalhista (PDT), Partido Verde (PV) e Partido da Social Democracia Brasileira (PSDB)) e maior para três partidos (Partido dos Trabalhadores (PT), Partido da República (PR) e Partido Comunista do Brasil (PCdoB)). Os outros dezoito partidos apresentam uma articulação essencialmente igual a do PMDB.

Sem dúvida os resultados observados quando permitimos a diferenciação entre os partidos indicam que há mais a se pesquisar nessa área. Não faz parte do escopo deste artigo, no entanto, avaliar a heterogeneidade da articulação intrapartidária por partido o que deixamos para pesquisas futuras. O que nos interessa destacar neste momento é que, embora a articulação intrapartidária possa ser diferente em função da estrutura e capilaridade de cada partido, há um efeito significante tanto em termos estatísticos quanto em termos substantivos para a grande maioria dos partidos.

Uma outra maneira de testarmos a robustez do nosso resultado seria nos concentrar nos maiores partidos em termos eleitorais. Seguimos, então, Carneiro e Almeida (2008) e trabalhamos com os sete partidos historicamente mais relevantes na arena eleitoral: Partido Progressista (PP), PDT, PT, Partido Trabalhista Brasileiro (PTB), PMDB, Democratas (DEM) e PSDB. Rodamos novamente as regressões implícitas na Tabela 1 apenas para esses partidos. Uma vez mais não notamos nenhuma mudança significativa; apenas perdemos precisão no caso da amostra mais reduzida ( $1 \%$ de margem). Se há alguma diferença entre a articulação intrapartidária desses partidos e dos demais, ela é no sentido inverso do que se poderia imaginar: há menos articulação para os partidos supostamente mais estruturados. No entanto, como a diferença é insignificante, é mais provável que não exista diferença entre os partidos (supostamente) mais estruturados e os menos estruturados. Uma vez mais esse resultado indica que há ainda muito a se pesquisar em relação à articulação intrapartidária em cada partido ${ }^{26}$. 
Ainda que a adição das variáveis por partido controlem boa parte das possíveis fontes de diferenciação nos nossos resultados, vale a pena verificar se não estamos confundindo a articulação intrapartidária com os vínculos com a coalizão estadual. Para checar essa possibilidade adicionamos uma variável binária que assume valor um quando o prefeito é do mesmo partido que o governador. Pode ser que esse tipo de vínculo favoreça tanto os votos do candidato a prefeito em 2008 como os votos dos candidatos a deputado federal em 2010. A adição dessa variável também não influencia os resultados de maneira significante, o que reforça nossa perspectiva de que estamos lidando com um efeito intrapartidário e não captando outros efeitos de maneira indireta.

Uma outra possibilidade que nos levaria a confundir o efeito partidário com outros efeitos ocorreria se os prefeitos eleitos sistematicamente se lançassem para deputado federal ou estadual no período subsequente. Nesse caso, não estaríamos observando a articulação intrapartidária, mas sim o prefeito trabalhando em benefício próprio ${ }^{27}$. Não acreditamos que esse seja o caso, pois, ao contrário do que se poderia imaginar, é raro que um prefeito se candidate a outro cargo. Apenas 30 prefeitos eleitos em 2008 se candidataram a algum cargo em 2010. Para a nossa amostra que se limita a municípios com menos de $200 \mathrm{mil}$ eleitores, esse número cai para apenas 14 . Na verdade, é bem mais usual um candidato a prefeito que ficou em segundo lugar se apresentar na eleição seguinte. Entre os candidatos a prefeito que em 2008 ficaram em segundo lugar, 167 concorreram a algum cargo em 2010. Isso é esperado porque um prefeito tem mais a perder disputando uma nova eleição com apenas dois anos de mandato.

De todo modo, verificamos se essa hipótese de benefício próprio teria algum sentido ou não adicionando uma variável binária indicando se o prefeito ou o segundo colocado foi candidato a deputado federal em 2010 ou não. Dado que a maioria dos que se candidatam a deputado são os candidatos derrotados na eleição municipal, o efeito dessa variável, se algum, seria o de aumentar a magnitude do impacto da articulação partidária. O fato é que o resultado de que existe alguma forma de articulação partidária, segundo a qual o prefeito funciona como um cabo eleitoral relevante para os deputados federais do seu partido, é bastante significativo resistindo a diversos testes de robustez ${ }^{28}$. 
Finalmente, realizamos mais uma tentativa de verificar a robustez dos resultados observando se, para deputado federal (Tabela 1), os resultados são replicados para a votação para deputado estadual no mesmo município. Na Tabela 3, reproduzimos as estimativas modificando a variável dependente de acordo com a nova análise. Em termos qualitativos, os resultados são virtualmente os mesmos. A correlação entre a eleição de prefeitos e a votação para deputado estadual na eleição subsequente é bastante clara. Portanto, há evidências para a existência de significativo efeito partidário também nas eleições para candidatos a deputado estadual.

Tabela 3

Impacto da Eleição para Prefeito (2008) para a Eleição para Deputado Estadual Subsequente (2010) por Diferentes Especificações e Amostras

\begin{tabular}{l|c|c}
\hline Covariadas e Restrição Amostral & OLS & Municípios \\
\hline Amostra completa & $0,0367^{*}$ & 5.211 \\
Amostra completa controlando por votos para vereadores & $0,0145^{*}$ & 5.211 \\
Margem de vitória no município $<5 \%$ & $0,0213^{*}$ & 1.374 \\
Margem de vitória no município $<3 \%$ & $0,0215^{*}$ & 823 \\
Margem de vitória no município $<1 \%$ & $0,0218^{* * *}$ & 266 \\
Margem de vitória no município < $1 \%$ e controlando por & & \\
votos para vereadores & $0,0198^{* * *}$ & 266 \\
\hline
\end{tabular}

Fonte: Tribunal Superior Eleitoral (TSE).

* Significativo a $1 \%$; ${ }^{* *}$ significativo a $5 \%$; *** significativo a $10 \%$ (desvio padrão robusto com cluster por município).

Existem, todavia, diferenças de magnitude no efeito partidário entre votação para o legislativo no nível estadual e no nível federal. Primeiramente, o impacto é significante apenas para o nível de $10 \%$ quando restringimos a amostra para 266 municípios com margem apertada de vitória na eleição para prefeito. Em segundo lugar, a magnitude das estimativas é sempre menor que as encontradas para os deputados federais. Apesar do valor de base para as eleições legislativas estaduais ser ligeiramente menor do que nas eleições para deputados federais ( $14 \%$ comparado com os 15\%), isto não é o suficiente para explicar as diferenças de magnitude. O efeito partidário relativo ao valor de base variará de um limite inferior de 10\% (1,5\% em valores absolutos) a um limite superior de $26 \%(3,7 \%)$, comparado com uma variação entre $21 \%$ e $37 \%$ encontrados para as votações para deputado federal no município. 
Não podemos dizer muito sobre essa diferença, dado que isto nos afastaria do foco deste artigo; entretanto, este é certamente um aspecto que merece investigação futura. Esperaríamos que o impacto fosse maior para os deputados estaduais por duas razões. Em primeiro lugar, o deputado estadual poderia ser mais atento aos problemas municipais. Pelo menos o deputado estadual reside no estado enquanto que outros participantes do Congresso Nacional residem em Brasília. Em segundo lugar, se acreditarmos que uma carreira política típica passaria do executivo municipal para o legislativo estadual e depois mover-se-ia para o legislativo federal, um ex-prefeito deveria estar mais conectado ao prefeito atual.

Para apoiar um impacto maior para o deputado federal, nós poderíamos também criar a hipótese de que esses políticos sejam mais relevantes para a política local que suas contrapartes estaduais. Isso é razoável, uma vez que as transferências federais para os municípios brasileiros em geral são maiores que as transferências estaduais. Adicionalmente, poderíamos considerar que essa diferença é o resultado de uma influência de cima para baixo do partido. Supondo que os deputados federais são mais influentes na organização partidária, isto refletiria que o prefeito trabalharia mais fortemente para eleger os líderes partidários.

De toda forma, o efeito partidário, como definido neste artigo, está presente em ambas as eleições, aumentando o grau de confiança do nosso resultado. Além disso, os resultados são robustos a uma série de testes o que nos dá bastante segurança no resultado. Nós ainda sabemos pouco sobre os mecanismos através dos quais esse efeito partidário ocorre e se as diferenças entre as duas eleições proporcionais pode revelar algo sobre este mecanismo. Nossa análise sugere, no entanto, que uma interessante via de pesquisa pode ser a de explorar mais profundamente a heterogeneidade dos impactos observados.

\section{CONCLUSÕES E PERSPECTIVAS FUTURAS}

Este artigo analisou os efeitos eleitorais das articulações intrapartidárias, um aspecto importante para entender a maioria dos sistemas políticos federativos. Exploramos as peculiaridades da federação brasileira para explorar a existência de coattail eleitorais reversos. Especificamente, nós exploramos a vantagem que um partido poderia ter, ao eleger o prefeito nas eleições de 2008, para as eleições proporcionais esta- 
duais de 2010. Nossas descobertas mostram evidências de um forte efeito coattail reverso, chamando a atenção para a importância das organizações partidárias municipais para entender os resultados nas eleições proporcionais estaduais. Esse resultado auxilia na compreensão do tamanho legislativo dos partidos brasileiros, um assunto central para entender a criação, manutenção e o rompimento das coalizões governamentais em um sistema partidário fragmentado.

As descobertas deste artigo também abrem possibilidades para futuras investigações. Um caminho óbvio é investigar detalhadamente os mecanismos causais, ou seja, como eleger um prefeito pode trazer vantagens eleitorais para os candidatos a deputado de seu partido. Mais especificamente, essa vantagem poderia vir do maior acesso dos prefeitos aos recursos públicos, do seu papel como implementadores de políticas públicas locais, como intermediários de transferências estaduais e federais, como emprestadores de credibilidade para as promessas eleitorais dos candidatos do partido, ou uma combinação destes diferentes aspectos. A resposta a esta pergunta somente poderá ser resolvida através de pesquisa empírica.

Outro aspecto importante a ser explorado mais detidamente são as articulações intrapartidárias, ou seja, por que seção partidária local do partido decide se empenhar para eleger os candidatos de seu partido que concorrem em distritos mais amplos. No caso específico deste artigo, por que a poiar os candidatos do seu partido nas eleições proporcionais estaduais que ocorrem dois anos depois. Se a existência de articulações intrapartidárias não é algo natural, então seria necessário explicar as condições nas quais elas ocorrem, ou seja, quais características organizacionais favorecem - ou dificultam - a cooperação entre os diferentes níveis partidários ${ }^{29}$.

Este último aspecto é fundamental para explorarmos mais detalhadamente a possível variação entre partidos brasileiros em sua capacidade de alcançar algum nível de articulação intrapartidária, um tema que foi apenas superficialmente discutido neste artigo devido à restrição no número de eleições apertadas. É possível que os partidos tenham diferentes níveis de articulação ou demonstrem diferentes trajetórias ao longo do tempo, apresentando padrões crescentes, estáveis ou decrescentes de articulação.

Voltando aos parágrafos iniciais, outro tópico interessante de pesquisa é o declínio da volatilidade eleitoral e a potencial consolidação da com- 
petição partidária entre os estados brasileiros. Conforme demonstrado por Bohn e Paiva (2009) e Peres et alii (2011), a volatilidade eleitoral diminuiu a taxas diferentes no nível estadual. Uma explicação possível para essa variação, ao menos para eleições legislativas, é que a volatilidade eleitoral diminui apenas em regiões onde os partidos políticos podem alcançar algum grau de articulação interna entre diferentes níveis de governo. Ou seja, nós deveríamos observar uma diminuição ainda maior da volatilidade eleitoral nos estados em que os partidos sejam capazes não apenas de manter seus votos no município, mas de transferir estes votos para os candidatos do partido nas eleições legislativas estaduais.

(Recebido para publicação em abril de 2012)

(Reapresentado em setembro de 2012)

(Aprovado para publicação em novembro de 2012) 


\section{Articulações Intrapartidárias e Desempenho Eleitoral no Brasil}

\section{NOTAS}

1. Veja-se, por exemplo, Braga (2006).

2. Ao analisar a volatilidade eleitoral no Brasil entre 1990 e 2006, Braga (2010) encontra um valor médio de 13,8\%, valor que situaria o Brasil na décima colocação entre os mesmos 39 países analisados.

3. Para uma análise da heterogeneidade da queda na volatilidade eleitoral entre os estados brasileiros no período mais recente, ver Bohn e Paiva (2009), Peres et alii (2011) e os trabalhos neles citados.

4. Embora com análise menos detalhada, o mesmo tema também foi abordado em Nicolau (2008).

5. Os mecanismos através dos quais essa vantagem se realiza podem ter várias explicações cuja análise mais precisa foge ao escopo do presente trabalho. Na conclusão, nós sugerimos algumas alternativas para investigação.

6. Embora os resultados empíricos ainda sejam motivo de debate, uma vertente importante da literatura argumenta que a descentralização do poder é um obstáculo para a articulação entre estes diferentes níveis e a formação de partidos nacionais. Veja-se, entre outros, os trabalhos de Cox (1997, 1999), Chibber e Kolman (1998, 2004), e Thorlakson (1999).

7. Para evitar confusões conceituais, nós evitamos utilizar o termo coordenação, tal como introduzido por Cox (1997, 1999 e 2005), pois a preocupação primária deste autor é com soluções estratégicas para o problema de existência de mais candidatos do que cargos em disputa. Mesmo que as soluções propostas por Cox assumam a existência de articulações intrapartidárias, a administração da relação entre os diferentes níveis partidários não é analisada como problema específico por este autor.

8. Para uma análise mais detalhada deste problema, ver Deschouwer (2003 e 2006), Leiras (2006), Van Houten (2009) e Thorlakson (2009 e 2011). Para o caso brasileiro, alguns trabalhos já enfocaram a questão da organização interna dos partidos, embora por outros ângulos que não o tipo de articulação intrapartidária tratada neste artigo; entre esses trabalhos, é possível citar Braga (2008), Braga et alii (2009) e Guarnieri (2004, 2009 e 2011).

9. Embora introduzido por Riker (1964), a importância das articulações intrapartidárias tem sido objeto de discussão em estudos recentes sobre o federalismo. Ver, por exemplo, os trabalhos de Filippov et alii (2004), Rodden (2006), Wibbels (2006).

10. Podem ser considerados como exceções os trabalhos Gélineau e Remmer (2005) para a Argentina e Gélineau e Belanger (2006) para o Canadá que analisam os efeitos das eleições presidenciais sobre as eleições provinciais. Outra exceção importante é o trabalho de Golder (2006) que investiga os efeitos do coattail presidencial sobre a fragmentação legislativa em um grupo de 35 regimes presidencialistas.

11. A única análise mais ampla sobre os coattail eleitorais reversos para o caso brasileiro, e de quem tomamos emprestado o termo, é Ames (1994), que lida com os efeitos da organização partidária municipal sobre as eleições presidenciais de 1989. Samuels (2000a e 2000b) encontra coattails eleitorais, mas afirma que, no Brasil, as candidaturas a governador teriam maior influência do que as candidaturas presidenciais na formação das listas de candidatos competindo nas eleições proporcionais estaduais. 


\section{George Avelino, Ciro Biderman e Leonardo S. Barone}

12. Em municípios com mais de 200 mil eleitores registrados, os prefeitos são eleitos por meio do mesmo sistema de dois turnos que regulamenta as eleições para presidente e para governadores de estado. Além disso, a reeleição está limitada a dois mandatos consecutivos (presidente, governadores e prefeitos). Todos os cargos legislativos (senadores, deputados federais ou estaduais e membros de câmaras municipais) não têm restrição de reeleição.

13. As limitações da descentralização brasileira pós-1988 são abordadas principalmente nos trabalhos de Arretche (2009 e 2010).

14. Sobre estes pontos, ver os já citados trabalhos de Braga (2008), Braga et alii (2009) e Guarnieri (2004, 2009 e 2011).

15. Guarnieri (2011) salienta que as direções partidárias estaduais e nacionais poderiam dificultar a organização de diretórios municipais representativos, pois prefeririam controlar o partido através da instituição de comissões provisórias. Segundo nossa interpretação, os partidos organizados no município através de comissões provisórias teriam mais dificuldade para eleger o prefeito - lembrar que Guarnieri salienta a dificuldade das comissões provisórias em lançar candidatos - mas, uma vez que lograssem eleger o prefeito, poderiam apresentar grau maior de articulação intrapartidária no estado. Estas questões merecem maior atenção no futuro.

16. A mobilização dos prefeitos para favorecer candidaturas estaduais de seu partido em estruturas políticas federativas exige um mínimo de articulação intrapartidária entre os níveis de governo. Para uma discussão sobre a articulação intrapartidária necessária para mobilizar os esforços dos prefeitos nas eleições estaduais na Argentina, ver Leiras (2006).

17. Como veremos a seguir, a variável que mede o efeito partidário é uma função da margem de vitória do partido ganhador da eleição municipal. A exclusão dos municípios com segundo turno se deve a dois motivos. O primeiro é o de que a estratégia dos partidos em municípios de segundo turno pode ser diferente daquela utilizada em municípios com eleições em apenas um turno. Atrelado a isso, o segundo motivo da exclusão é o de que, como atestado por imensa literatura desde Duverger (1954), as eleições majoritárias com apenas um turno tendem a convergir para apenas duas listas competitivas que representariam a grande maioria do eleitorado; este último aspecto torna a diferença do primeiro para o segundo colocado uma boa medida da competitividade no município.

18. Por exemplo, alguns comentaristas sugeriram que a derrota de Gabeira no segundo turno da eleição carioca de 2008 deveu-se em parte ao fato de que o segundo turno caiu em um feriado e que os eleitores de Gabeira estariam mais propensos a viajar no feriado do que os eleitores de seu desafiante.

19. Agradecemos a um parecerista anônimo por ter nos chamado a atenção para este problema.

20. Na realidade condicionamos na função polinomial sobre a margem de vitória. Em termos da especificação (1) a função $V\left(x_{m, p, t} ; \beta\right)$ permanece, mas a somatória em geral não é utilizada. Apenas em algumas especificações utilizamos a proporção de votos para vereador do partido como uma covariável. Nenhuma outra covariável foi utilizada nas especificações apresentadas.

21. Dois pontos são importantes sobre a determinação do valor de base. O primeiro é que, no mesmo município, o percentual esperado de votos obtidos por um partido 
em eleições majoritárias - no caso, prefeitos - deve ser maior que o de votos do mesmo partido em nas eleições proporcionais estaduais, principalmente, em distritos de grande magnitude como o caso dos estados brasileiros. O segundo ponto é que o valor de base deveria conter apenas o desempenho eleitoral nas eleições estaduais dos partidos que ficaram em segundo lugar nas eleições para prefeito; portanto, ao adotarmos a média como o desempenho eleitoral esperado para as eleições estaduais, nós estamos inflando o valor de base, ao incluir também o desempenho dos partidos que elegeram o prefeito.

22. Vale destacar que a regressão descontínua não deve ser interpretada como o efeito apenas sobre a subpopulação próxima da descontinuidade, mas sim como o efeito sobre toda a população com pesos mais elevados para as observações próximas da descontinuidade.

23. Essas questões nos foram levantadas por parecerista anônimo, ao qual agradecemos pelas sugestões.

24. O PMDB ficou em primeiro ou segundo em mais de 2 mil disputas na nossa amostra.

25. Note-se que adicionamos 50 novas variáveis pois temos 26 partidos (portanto, 25 variáveis identificando os partidos) e interagimos cada uma dessas com a variável de tratamento.

26. Por economia de espaço, não apresentamos os resultados que, entretanto, podem ser requisitados aos autores.

27. Esse ponto também nos foi sugerido por um parecerista anônimo.

28. Novamente, por economia de espaço, não apresentamos os resultados que podem ser requisitados aos autores.

29. Para uma discussão sobre este ponto ver Leiras (2006) e Van Houten (2009). 


\section{George Avelino, Ciro Biderman e Leonardo S. Barone}

\section{REFERÊNCIAS BIBLIOGRÁFICAS}

AMES, Barry. (1994), "The Reverse Coattails Effect: Local Party Organization in the 1989 Brazilian Presidential Election". American Political Science Review, vol. 88, no 1, pp. 95-111.

ARRETCHE, Marta. (2009), “Continuidades e Descontinuidades da Federação Brasileira: De como 1988 Facilitou 1995". Dados, vol. 52, no 2, pp. 377-423.

. (2010), “Federalismo e Igualdade Territorial: Uma Contradição em Termos?”. Dados, vol. 53, no 3, pp. 587-620.

BOHN, Simone R. e PAIVA, Denise. (2009), A Volatilidade Eleitoral nos Estados; Sistema Partidário e Democracia no Brasil. Revista de Sociologia e Política, vol. 17, no 3, pp. $187-208$

BRAGA, Maria do Socorro. (2006), O Processo Partidário-Eleitoral Brasileiro: Padrões de Competição Política, 1982-2002. São Paulo, Ed. Humanitas.

. (2008), "Organização Partidária e Seleção de Candidatos no Estado de São Paulo". Opinião Pública, vol. 14, no 2, pp. 454-485.

. (2010), “Eleições e Democracia no Brasil: A Caminho de Partidos e Sistemas Partidários Institucionalizados". Revista Brasileira de Ciência Política, no 4, pp. 43-73.

, VEIGA, Luciana F. e MIRÍADE, Angel. (2009), “Recrutamento e Perfil dos Candidatos Eleitos à Câmara dos Deputados nas Eleições de 2006". Revista Brasileira de Ciências Sociais, vol. 24, no 70, pp. 123-142.

BRAMBOR, Thomas e CENEVIVA, Ricardo. (2012), “Reeleição e Continuismo nos Municípios Brasileiros". Novos Estudos Cebrap, no 93, pp. 9-21.

BROLLO, Fernanda e NANNICINI, Tommaso. (2012), “Tying your Enemy's Hands in Close Races: The Politics of Federal Transfers in Brazil". American Political Science Review, vol. 106, no 4, pp. 742-761.

CARNEIRO, Leandro P. e ALMEIDA, Maria Hermínia T. (2008), “Definindo a Arena Política Local: Sistemas Partidários Municipais na Federação Brasileira". Dados, vol. 51, no 2, pp. 403-432.

CHIBBER, Pradeep e KOLMAN, Ken. (1998), "Party Aggregation and the Number of Parties in India and the United States". American Political Science Review, vol. 92, no 2, pp. 329-342.

(2004), The Formation of National Party Systems: Federalism and Party Competition in Canada, Great Britain, India, and the United States. Princeton, Princeton University Press.

COX, Gary W. (1997), Making Votes Count: Strategic Coordination in the World's Electoral Systems. Cambridge/New York, Cambridge University Press.

. (1999), “Electoral Rules and Electoral Coordination”. Annual Review of Political Science, vol. 2, no 1, pp. 145-161.

(2005), "Electoral Institutions and Political Competition; coordination, persuasion and mobilization". Handbook of New Institutional Economics. C. Ménard and M. M. Shirley, Springer. pp. 69-89. 
DESCHOUWER, Kris. (2003), "Political Parties in Multi-Layered Systems". European Urban and Regional Studies, vol. 10, no 3, pp. 213-226.

. (2006), “Political Parties as Multi-Level Organizations”. Handbook of Party Politics. R. S. Katz and W. Crotty. London, Sage Publications.

DUVERGER, Maurice. (1954), Political Parties. New York, John Wiley.

FILIPPOV, Mikhail; ORDESHOOK, Peter C.; SHVETSOVA, Olga. (2004), Designing Federalism: A Theory of Self-Sustainable Federal Institutions. Cambridge, Cambridge University Press.

GELINEAU, François e BÉLANGER, Eric. (2005), “Electoral Accountability in a Federal System: National and Provincial Economic Voting in Canada". Publius, vol. 35, oㅡ 3, pp. 407-424.

GELINEAU, François e REMMER, Karen L. (2006), “Political Decentralization and Electoral Accountability: The Argentine Experience, 1983-2001". British Journal of Political Science, vol. 36, № 1, pp. 133-157.

GOLDER, Matt. (2006), "Presidential Coattails and Legislative Fragmentation". American Journal of Political Science, vol. 50, no 1, pp. 34-48.

GUARNIERI, Fernando. (2004), Partidos, Seleção de Candidatos e Comportamento Político. Dissertação de Mestrado, Programa de Pós-Graduação em Ciência Política, Universidade de São Paulo.

. (2009), A Força dos Partidos Fracos: Um Estudo sobre a Organização dos Partidos Brasileiros e seu Impacto na Coordenação Eleitoral. Tese de Doutorado, Programa de Pós-Graduação em Ciência Política, Universidade de São Paulo.

. (2011), “A Força dos Partidos Fracos". Dados, vol. 54, no 1, pp. 235-258.

KATZ, Jonathan N. e KING, Gary. (1999), “A Statistical Model for Multiparty Electoral Data". American Political Science Review, vol. 93, no 1, pp. 15-32.

LEE, David S. (2008), "Randomized Experiments from Non-random Selection in U.S. House Elections". Journal of Econometrics, vol. 142, no 2, pp. 675-697.

LEIRAS, Marcelo. (2006), Parties, Provinces, and Electoral Coordination: A Study of Party and Party System Aggregation in Argentina, 1983-2005. Tese de Doutorado, Programa de Pós-Graduação em Ciência Política, Universidade de Notre Dame.

MAINWARING, Scott e TORCAL, Mariano. (2006), “Party System Institutionalization and Party System Theory After the Third Wave of Democratization". Handbook of Party Politics. R. S. Katz and W. Crotty. London, Sage Publications.

NICOLAU, Jairo. (2008), “O que 2008 Tem a Ver com 2010?” Análise de Conjuntura, no 12, pp. 10-16.

PERES, Paulo; RICCI, Paolo e RENNÓ, Lúcio. (2011), “A Variação da Volatilidade Eleitoral no Brasil". Latin American Research Review, vol. 48, no 3, pp. 46-68.

RIKER, William H. (1964), Federalism: Origin, Operation, Significance. Boston, Little.

RODDEN, Jonathan. (2006), Hamilton's Paradox: The Promise and Peril of Fiscal Federalism. Cambridge, Cambridge University Press. 


\section{George Avelino, Ciro Biderman e Leonardo S. Barone}

SAMUELS, David J. (2000a), “The Gubernatorial Coattails Effect: Federalism and Congressional Elections in Brazil". The Journal of Politics, vol. 62, no 1, pp. 240-253.

. (2000b), "Concurrent Elections, Discordant Results: Presidentialism, Federalism, and Governance in Brazil". Comparative Politics, vol. 33, no 1, pp. 1-20.

TITIUNIK, Rocío. (2009), “Incumbency Advantage in Brazil: Evidence from Municipal Mayor Elections". Working Paper. Disponível em http://wwwpersonal.umich.edu/titiunik/papers/Titiunik IABrazil.pdf.

THORLAKSON, Lori. (2009), "Patterns of Party Integration, Influence and Autonomy in Seven Federations". Party Politics, vol. 15, no 2, pp. 157-177.

. (2011), "Measuring Vertical Integration in Parties with Multi-level Systems Data". Party Politics, Sage Publications, July.

TOMZ, Michael; TUCKER, Joshua e WITTENBERG, Jason. (2002), “An Easy and Accurate Regression Model for Multiparty Electoral Data". Political Analysis, vol. 10, no 1, pp. 66-83.

VAN HOUTEN, Pieter. (2009), "Multi-Level Relations in Political Parties". Party Politics, vol. 15, no 2, pp. 137-156.

WIBBELS, Erik. (2006), “Madison in Baghdad? Decentralization and Federalism in Comparative Politics". Annual Review of Political Science, vol. 9, pp. 165-188. 


\section{ABSTRACT \\ Intra-Partisan Linkage and Electoral Performance in Brazil}

Do Brazil's political parties matter in elections? The article focuses on this problem by analyzing whether a mayor's election influences his party's electoral performance in the same city. A regression discontinuity model (RDM) was used to identify the causal effect of mayors on their party's electoral performance in elections to National and State Deputies. The findings suggest that a mayor's election (even by a difference of only 1\%) should increase the votes for the same party in the elections to both National and State Deputy. This result is interpreted as evidence of intra-partisan linkage, whereby mayors act systematically to help elect National and State Deputies from their own parties.

Key words: political parties; elections; party organization; decentralization; Federalism

\section{RÉSUMÉ}

\section{Articulations Internes des Partis et Performance Électorale au Brésil}

Les partis politiques brésiliens sont-ils importants sur le plan électoral? Cet article se consacre à ce problème en analysant si l'élection d'un maire influence les résultats électoraux de son parti dans la même commune. Un Modèle de Régression Discontinue (RDD) est utilisé pour identifier l'influence des maires sur les résultats électoraux de leur parti lors de l'élection de députés tant au niveau fédéral que de l’État. Les résultats obtenus suggèrent que l'élection d'un maire (même lorsque sa victoire n'est due qu'à $1 \%$ de différence) devra augmenter les scores du même parti aux élections législatives, que ce soit sur le plan fédéral ou de l'état. Ce résultat est interprété comme une évidence de l'articulation interne des partis, les maires agissant systématiquement en faveur des candidats au poste de député fédéral de leur propre parti.

Mots-clés: partis politiques; élections; organisation des partis; décentralisation; fédéralisme 